\title{
One-Pot Synthesis of Tetrahydroisoquinolines via Benzene Ring Annulation
}
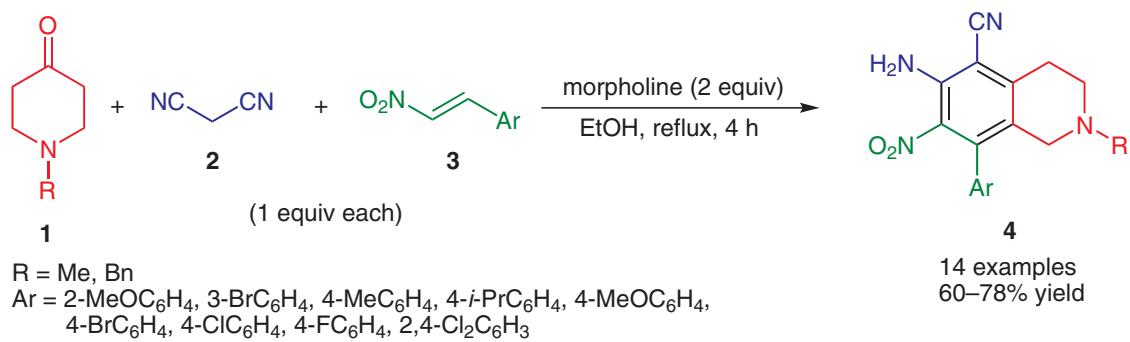

Michael addition<smiles>O=C1CCCC1</smiles>

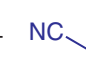

2 (1 equiv each) 3 5 $\mathrm{n}=1,2$ $\mathrm{Ar}=4-\mathrm{MeC}_{6} \mathrm{H}_{4}, 4-\mathrm{ClC}_{6} \mathrm{H}_{4}$ $\underset{\text { EtOH, reflux, } 4 \mathrm{~h}}{\stackrel{\text { morpholine (2 equiv) }}{\longrightarrow}}$<smiles>N#Cc1c(N)c([N+](=O)[O-])c(Br)c2c1CCC2</smiles>

4 examples $70-75 \%$ yield
Significance: While most of the classical ways for the preparation of tetrahydroisoquinolines have involved heteroannulation approaches (e.g. PictetSpengler reaction, see first Review), the present work reports an unusual one-pot three-component strategy involving benzene ring annulation to afford polyfunctionalized tetrahydroisoquinolines

4. The three-component, one-pot reaction of commercially available piperidin-4-ones $\mathbf{1}$ as heterocyclic precursor, malononitrile (2), $\beta$-nitrostyrenes 3, and morpholine as base were found to be the optimal conditions to obtain products 4 in 60$78 \%$ yields. The reaction is believed to proceed through a domino mechanism, bringing into play three named reactions: 1) Knoevenagel reaction between $\mathbf{1}$ and $\mathbf{2}$; 2) Michael addition to $\mathbf{3}$; 3) Thorpe-Ziegler cyclization-tautomerization followed by aromatization under air atmosphere. The structure of $\mathbf{4}$ was confirmed by single crystal $X$-ray crystallographic analysis. This reaction was applied to the synthesis of carbocycles $\mathbf{6}$ in high yields starting from cyclic ketones 5.

SYNFACTS Contributors: Victor Snieckus, Emilie David Synfacts 2011, 4, 0363-0363 Published online: 18.03.2011 Dol: 10.1055/s-0030-1259671; Reg-No.: V01611SF
Comment: The tetrahydroisoquinoline skeleton is commonly encountered in natural products as well as in bioactive molecules and drugs, for example, tubocurarine chloride, an alkaloid used as a skeletal muscle relaxant (A. J. Everett, L. A. Lowe, S. Wilkinson J. Chem. Soc. D 1970, 1020) or nomifensine and dichlofensine, two synthetic molecules used as antidepressant drugs (see second Review). The present methodology combines originality by building the benzene ring of the tetrahydroisoquinoline scaffold, and efficiency by generating three double bonds in a single-pot operation and in high yields. The starting materials are inexpensive and the reaction is very easy to carry out. The resulting highly functionalized tetrahydroisoquinolines $\mathbf{4}$ may be subjected to further chemistry.

Reviews: E. D. Cox, J. M. Cook Chem. Rev. 1995, 95, 1797-1842; R. N. Brogden, R. C. Heel, T. M. Speight, G. S. Avery Drugs 1979, 18, 1-24. 